\title{
INFLUÊNCIA DA COMPOSIÇÃO QUÍMICA, POROSIDADE E ENVELHECIMENTO NAS PROPRIEDADES MECÂNICAS DE LIGAS AL-SI-MG FUNDIDAS
}

\author{
Albino Moura Guterres ' \\ Claudio André Lopes de Oliveira ' \\ Carlos Alexandre dos Santos ${ }^{2}$
}

\section{Resumo}

O objetivo do presente trabalho foi analisar a influência da composição química, porosidade e efeitos dos tratamentos térmicos em algumas propriedades mecânicas em ligas de Al-Si-Mg fundidas. Duas ligas de Al-3,8\%Si-0,25\%Mg (Liga I) e Al-6,5\%Si-0,6\% Mg (Liga II) foram preparadas, fundidas e solidificadas em molde metálico, com e sem processo de desgaseificação. Amostras foram obtidas para análises do percentual de porosidade e determinação das propriedades mecânicas. Parte das amostras foram submetidas a tratamentos térmicos de endurecimento por precipitação. Em relação à porosidade, observou-se que a Liga II apresentou maior percentual de porosidade por conter mais $\mathrm{Si}$ e $\mathrm{Fe}$ na sua composição química. Após as análises das propriedades mecânicas, observou-se que, com a aplicação do tratamento térmico, a Liga II apresentou os melhores resultados, gerando aumento de $25 \%$ na resistência à tração e $23 \%$ na dureza. $\mathrm{Na}$ análise da correlação da composição química, percentual de porosidade e efeitos dos tratamentos térmicos com a variação nas propriedades mecânicas, modelos matemáticos que permitem prever o limite de resistência à tração e dureza nestas ligas foram desenvolvidos.

Palavras-chave: Ligas de Al-Si-Mg; Endurecimento por precipitação; Porosidade; Propriedades mecânicas.

\section{INFLUENCE OF CHEMICAL COMPOSITION, POROSITY AND AGING IN THE MECHANICAL PROPERTIES OF AL-SI-MG ALLOYS}

\begin{abstract}
The main objective of this work was to analyze the influence of chemical composition, porosity and the effects of heat treatments on some mechanical properties in the Al-Si-Mg as-cast alloys. Two alloys of Al-3,8\% Si-0,25\% Mg (Alloy I) and $\mathrm{Al}-6,5 \% \mathrm{Si}-0,6 \% \mathrm{Mg}$ (Alloy II) were prepared, cast and solidified in metal mold, with without degassing process. Samples were extracted for percentage of porosity analysis and mechanical properties determination. Part of the samples were subjected to precipitation hardening heat treatments. In relation to the porosity, it was observed that the alloy II presented higher percentage of porosity because it contained more Si and Fe in its chemical composition. Regarding mechanical properties analyses, the alloy II presented the best results, resulting in an increase of $25 \%$ in the tensile strength and $23 \%$ in the hardness when heat treatment was applied. In the analysis of the correlation between chemical composition, percentage of porosity and the effects of the heat treatments with the variation in the mechanical properties, it was developed mathematical models that allow to predict the tensile strength and hardness in these $\mathrm{Al}-\mathrm{Si}-\mathrm{Mg}$ alloys.
\end{abstract}

Keywords: Al-Si-Mg alloys; Precipitation hardening; Porosity; Mechanical properties.

\section{INTRODUÇÃO}

O uso de peças fundidas de alumínio tem aumentado drasticamente ao longo das últimas três décadas no mais diversos setores de engenharia [I]. A excelente fluidez, os custos de produção relativamente baixos, e a alta resistência em relação ao peso fazem das ligas fundidas de $\mathrm{Al}-\mathrm{Si}-\mathrm{Mg}$ uma opção atraente para produção de peças de alta resistência com baixo peso nas indústrias automotiva, aeronáutica e aeroespacial [2].

Conforme Kaeel [3], o sistema de ligas alumínio-silício é um dos mais importantes para a indústria de fundição,

'Instituto Federal Sul-rio-grandense, Passo Fundo, RS, Brasil. E-mail: albino.moura@passofundo.ifsul.edu.br

${ }_{2}^{2}$ Pontifícia Universidade Católica do Rio Grande do Sul - PUCRS, Porto Alegre, RS, Brasil.

2I 76-I523 (c) 2019 Associação Brasileira de Metalurgia, Materiais e Mineração. Published by ABM. This is an open access paper, published under the Creative Commons CC BY-NC-ND license (Attribution-NonCommercial-NoDerivs) - https://creativecommons.org/licenses/ by-nc-nd/4.0/. 
principalmente devido à sua alta fluidez conferida pela presença do eutético AlSi. A adição de magnésio torna as ligas tratáveis termicamente. Desta forma, as ligas de Al-Si-Mg são atualmente as mais populares para obtenção de peças fundidas comerciais, e dois importantes membros desta família são as ligas A356 e A357 (seguindo as designações de liga do Aluminum Association). Para essas ligas, a Aluminum Association [4] específica as composições químicas conforme apresentadas na Tabela I.

A aplicação de tratamentos térmicos modifica as características microestruturais e melhoraram as propriedades tecnológicas das ligas Al-Si-Mg. O tratamento térmico de endurecimento por precipitação (T6) é o método mais comum para aumentar a resistência das ligas. Segundo Manente e Timelli [5], o tratamento térmico compreende três fases: solubilização, resfriamento rápido e envelhecimento, podendo este ser natural ou artificial.

Manente e Timelli [5], consideram que um tratamento térmico de solubilização de 6 horas a $540^{\circ} \mathrm{C}$ é suficiente para dissolver completamente as fases ricas em magnésio e para conseguir uma solução sólida homogênea. Já em relação as temperaturas utilizadas na etapa de envelhecimento geralmente variam entre $175^{\circ} \mathrm{C}$ a $240^{\circ} \mathrm{C}[5,6]$. Dioni et al. [6] analisaram diferentes temperaturas e tempos no tratamento de envelhecimento e seus reflexos nas propriedades mecânicas de tração e dureza em uma liga A356, nesta pesquisa Dioni et al. [6] salientaram que a liga apresentou os valores máximos de resistência à tração e de dureza nas amostras envelhecidas a uma temperatura de $180^{\circ} \mathrm{C}$ durante 4 horas.

As propriedades mecânicas das ligas fundidas de alumínio são significativamente dependentes de suas características macroestruturais e microestruturais. O tamanho e a morfologia dos grãos cristalinos e os espaçamentos dendríticos primários e secundários influenciam nas propriedades mecânicas das peças fundidas [7]. Por sua vez, as taxas de resfriamento durante a solidificação definem as características dos grãos e dos braços dendríticos [8], e consequentemente, afetam diretamente as propriedades mecânicas finais.

Segundo Puparattanapong e Limmaneevichitr [9], nas peças fundidas de ligas de alumínio, a porosidade é o defeito que ocorre mais frequentemente. A presença de porosidade é acompanhada por um decréscimo nas propriedades mecânicas, como tensão de ruptura, ductilidade, resistência à fadiga, etc. A porosidade é considerada a principal causa de rejeição das peças fundidas nas aplicações industriais.

Neste sentido, o presente estudo pretende analisar a influência da composição química, porosidade e efeitos dos tratamentos térmicos de endurecimento por precipitação em algumas propriedades mecânicas em ligas de $\mathrm{Al}-\mathrm{Si}-\mathrm{Mg}$ fundidas, obtendo equações que permitam estimar as propriedades mecânicas (limite de resistência à tração e dureza) para as condições analisadas.

\section{METODOLOGIA}

Para $\circ$ presente trabalho, foram preparadas ligas do sistema Al-Si-Mg com duas composições distintas (Liga I: Al-3,8\%Si-0,25\%Mg e Liga II: Al-6,5\%Si-0,6\%Mg - \% em massa). As ligas foram produzidas a partir da fusão de alumínio primário (99,2\% de pureza), alumínio-silício eutético ( $12 \%$ de silício) e magnésio metálico ( $99,8 \%$ de pureza). Objetivou-se obter a Liga II com composição química semelhante à liga comercial A356, já em relação à Liga I, buscou-se reduzir a presença dos elementos de liga em torno de $50 \%$ em relação à Liga II, com a finalidade de analisar a influência da composição química na variação das propriedades mecânicas.

As ligas foram fundidas em forno tipo poço e cadinho de grafite. A temperatura do forno foi mantida entre $720^{\circ} \mathrm{C}$ e $730^{\circ} \mathrm{C}$, o que corresponde a aproximadamente $15 \%$ de superaquecimento acima da Temperatura Liquidus das ligas. As temperaturas de vazamento do metal líquido foram em torno de $700^{\circ} \mathrm{C}$, devido à perda de calor durante a retirada do cadinho do forno e durante o preenchimento do molde. O molde metálico (lingoteira) foi confeccionado em aço inoxidável AISI 304, com diâmetro interno de $44 \mathrm{~mm}$, altura de $180 \mathrm{~mm}$ e espessura de parede de $13 \mathrm{~mm}$. O molde foi pré-aquecido a $400^{\circ} \mathrm{C}$ com o objetivo de permitir o completo preenchimento do mesmo pelo metal líquido antes do início da solidificação. Em todos os experimentos, a extração de calor do sistema metal/molde foi realizada sem o auxílio de sistema de resfriamento forçado, ocorrendo por condução nas paredes do molde e convecção-radiação na superfície do metal. No total, foram produzidos 8 lingotes para cada liga em condições idênticas de solidificação. Para cada uma das ligas, a solidificação do primeiro lingote foi monitorada com termopares estrategicamente posicionados na cavidade do molde, permitindo a obtenção dos perfis de temperatura durante a solidificação. As posições dos termopares são apresentadas na Figura I.

Metade dos lingotes, de ambas as ligas, foram submetidos a processo de desgaseificação. Durante a fusão, o metal líquido foi desgaseificado com 15 gramas de pastilhas de Hexacloroetano $\left(\mathrm{C}_{2} \mathrm{Cl}_{6}\right)$, com auxílio de sino de imersão

Tabela I. Composição química das ligas 356.0 e 357.0

\begin{tabular}{cccccccccc}
\hline \multirow{2}{*}{ Liga } & \multicolumn{7}{c}{ Faixas para composição química e limites máximos (\%) } \\
\cline { 2 - 10 } & $\mathbf{S i}$ & Fe & Cu & Mn & Mg & Zn & Ti & Outros \\
\hline A356 & $6,5-7,5$ & 0,60 & 0,25 & 0,35 & $0,2-0,45$ & 0,35 & 0,25 & 0,15 \\
A357 & $6,5-7,5$ & 0,15 & 0,05 & 0,03 & $0,45-0,6$ & 0,05 & 0,2 & 0,15 \\
\hline
\end{tabular}

Fonte: ASM Handbook Casting [4]. 


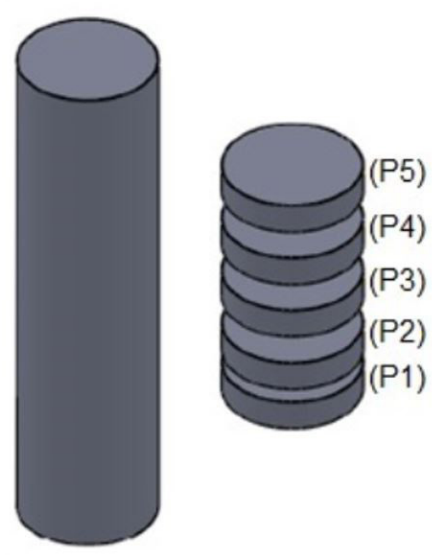

(a)

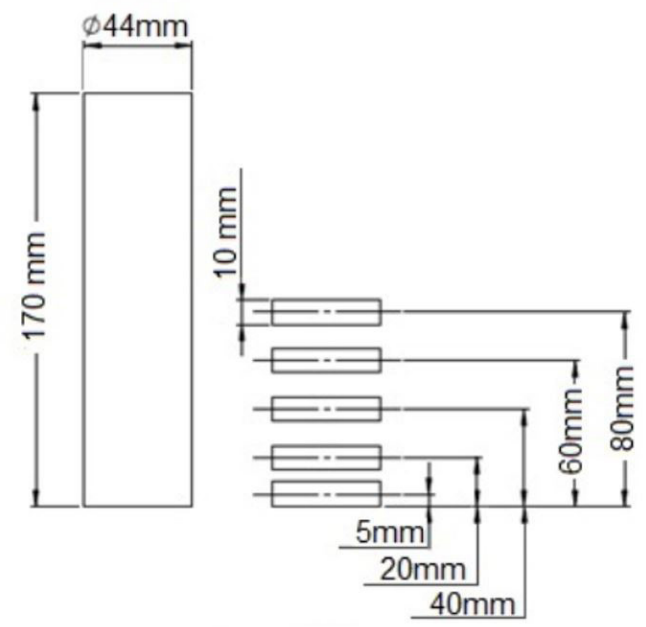

(b)

Figura I. Disposição das amostras para realização do estudo. (a) vista tridimensional, (b) vista ortogonal.

e tempo de espera de 5 minutos. Estes parâmetros foram determinados conforme as recomendações do fabricante das pastilhas de Hexacloroetano, o qual determina que a quantidade de pastilha a ser utilizada fique entre I a I,5\% da massa da liga a ser desgaseificada e também, a manutenção da pastilha no fundo do banho até que o borbulhamento tenha cessado totalmente. Os lingotes restantes não sofreram processo de desgaseificação. Durante a fusão, as ferramentas como sino e lanças utilizadas foram de aço inoxidável AISI 304.

A partir dos lingotes produzidos foram retiradas amostras da seção transversal circular utilizadas para a análise do percentual de porosidade e determinação das propriedades mecânicas. As amostras foram obtidas realizando cortes transversais ao longo do comprimento dos lingotes. As amostras retiradas foram denominadas de PI, P2, P3, P4, P5 e foram obtidas a uma distância da base da lingoteira de $5 \mathrm{~mm}, 20 \mathrm{~mm}, 40 \mathrm{~mm}, 60 \mathrm{~mm}$ e $80 \mathrm{~mm}$, respectivamente, conforme observa-se na Figura I, com os centros geométricos das amostras coincidentes com as posições onde se localizavam os termopares.

$\mathrm{Na}$ análise da porosidade foram utilizadas todas as amostras de seção transversal circular obtidas para as diferentes condições (bruta de solidificação sem desgaseificação e brutas de solidificação desgaseificadas), referentes às Ligas I e II. Essa análise antecedeu os demais procedimentos, e foram realizadas, para cada liga, 4 medidas para cada condição e posição em análise, sendo que, ao final, obteve-se a média dos valores e o intervalo de dispersão.

Para medir a porosidade, usou-se a técnica denominada picnometria [10], que é um processo de comparação das massas específicas relativas do sólido e do líquido, onde foi possível medir a massa específica aparente das amostras. O método picnométrico empregado é conforme a técnica proposta por Moutinho [I I], que se baseia na norma ASTM
B3 I I-93 [ I 2] (reaprovada em 2002). Após a determinação da massa específica aparente $\left(\rho_{A}\right)$ das amostras, foi possível estimar a porosidade, utilizando a Equação I:

$$
\% \text { Poros }=\left[\frac{T-A}{T}\right] * 100
$$

onde: $\rho_{T}$ : massa específica teórica das amostras;

Para determinar a massa específica teórica das amostras, foi utilizada a porcentagem em massa dos elementos químicos obtidos na caracterização química realizada por Espectômetria de Emissão Óptica. Com a porcentagem em massa de cada elemento constituinte das ligas, buscou-se na bibliografia [13] a massa específica de cada elemento e calculou-se a massa específica teórica das ligas em estudo, conforme representado pela Equação 2

$$
T=\sum_{i=1}^{n} x_{i} *_{i}
$$

onde: $x_{i}$ : porcentagens em massa do componente $i$; $\rho_{i:}$ massa específica do componente $i$.

A metade das amostras obtidas para as diferentes condições e posições em análise, referentes às Ligas I e II, foram submetidas ao tratamento térmico de envelhecimento por precipitação (T6), sendo a etapa de solubilização realizada na temperatura de $540^{\circ} \mathrm{C} \pm 10^{\circ} \mathrm{C}$, durante $6 \mathrm{~h}$, seguido de resfriamento em água morna na temperatura entre $60^{\circ} \mathrm{C} \pm 5^{\circ} \mathrm{C}$. $O$ envelhecimento artificial foi realizado na temperatura de $180^{\circ} \mathrm{C}$, durante período de 4 horas. Os tempos e temperaturas escolhidos nas etapas do tratamento térmico foram baseados de acordo com as pesquisas desenvolvidas por Manente e Timelli [5] e Dioni et al. [6], conforme já mencionados no capítulo da introdução desse estudo.

$\mathrm{Na}$ sequência, amostras para todas as posições em análise e condições (bruta de solidificação sem desgaseificação, bruta de solidificação desgaseificada, sem desgaseificação 
tratada termicamente e desgaseificada tratada termicamente) foram utilizadas para medição de dureza. Foram retirados de cada amostra dois corpos de prova para ensaio de tração, sendo obtido no total, para cada uma das ligas, 4 corpos de prova para cada condição e posição. Na Figura 2 observa-se as amostras onde foram realizados os ensaios de dureza (seção transversal em destaque) e onde foram retirados os corpos de prova para ensaio de tração. Os corpos de prova, para ensaio de tração foram obtidos com dimensões reduzidas proporcionais ao modelo padrão, conforme especificado pela norma ASTM E8M-04 [14].

Para obtenção das durezas nas amostras aplicou-se as técnicas de ensaio de dureza Brinell. Para isso, utilizou-se um Durômetro Brinell, um penetrador esférico de aço de $\varnothing 5 \mathrm{~mm}$, uma carga de $2500 \mathrm{~N}$ (250 kgf) e tempo de penetração de 20 segundos, segundo a norma ABNT NBR NM ISO 6506-I:20 I0 [I5]. Foram realizadas três medidas em cada amostra.

Os ensaios de tração, para determinação do limite de resistência à tração (LRT) foram executados utilizando a máquina de ensaios, com capacidade de $10.000 \mathrm{~N}$, sistema de aquisição de dados do próprio fabricante, com uma velocidade de ensaio em torno de $4 \mathrm{~mm} / \mathrm{s}$. Os ensaios foram realizados conforme a norma ASTM E8M-04 [14].

Por último, foram obtidas expressões matemáticas, através de técnicas estatísticas de regressão linear múltipla, utilizando-se o software estatístico Minitab 17, com objetivo de relacionar as propriedades mecânicas em função da composição química, percentual de porosidade e as condições em análise (brutas de solidificação e tratadas termicamente). Para a construção desses modelos matemáticos, foi necessário organizar as variáveis. Como variáveis dependentes foram escolhidas o "Limite de Resistência à Tração" e a "Dureza”, que são propriedades comumente utilizadas na formulação matemática para realização de projetos mecânicos. Já como variáveis independentes foram escolhidas: a "Composição Química", composta pelos elementos Silício, Ferro e Magnésio; a variável "Percentual de Porosidade"; o "Tratamento Térmico", que foi considerado como uma variável qualitativa.

\section{RESULTADOS}

Após a preparação das cargas, fusão e solidificação das Ligas I (Al-3,8\%Si-0,25\%Mg) e II (Al-6,5\%Si-0,6\%Mg), obteve-se a caracterização da composição química das mesmas por Espectroscopia de Emissão Óptica, conforme a Tabela 2.

Comparando a composição química das Ligas I (Al-3,8\%Si-0,25\%Mg) e II (Al-6,5\%Si-0,6\%Mg), observa-se que a Liga I apresenta os teores de $\mathrm{Si} \mathrm{e} \mathrm{Mg} \mathrm{aproximadamente}$ $42 \%$ e $58 \%$, respectivamente, menores do que os obtidos na Liga II. Constatou-se também, que além dos elementos químicos principais $\mathrm{Al}, \mathrm{Si}$ e $\mathrm{Mg}$, o elemento químico $\mathrm{Fe}$ apresentou-se com teor significativo, oriundo da matéria prima e ferramentas utilizadas no processo de fusão.

Em todos os processos de fusão e solidificação, as temperaturas de fusão, de vazamento e aquecimento da lingoteira mantiveram-se similares. A partir das curvas de resfriamento obtidas pelos termopares, foram determinados os tempos de passagem da Isotermas Liquidus em função das posições, correspondendo ao início da solidificação (Figura 3a). Conforme observa-se praticamente todas as posições apresentaram tempos muito próximos de início de solidificação devido à dinâmica de preenchimento do molde e equalização das temperaturas em todo metal líquido.

A partir dos perfis térmicos, foram determinadas as taxas de resfriamento no líquido para cada posição dos termopares (Figura 3b). Os valores encontrados são muito próximos, e praticamente constantes para as duas ligas,

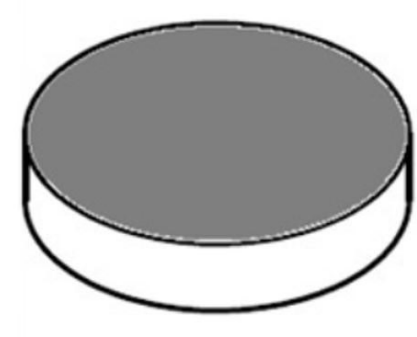

(a)

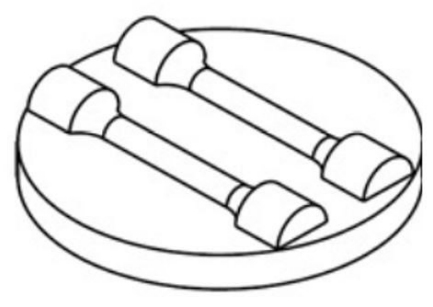

(b)

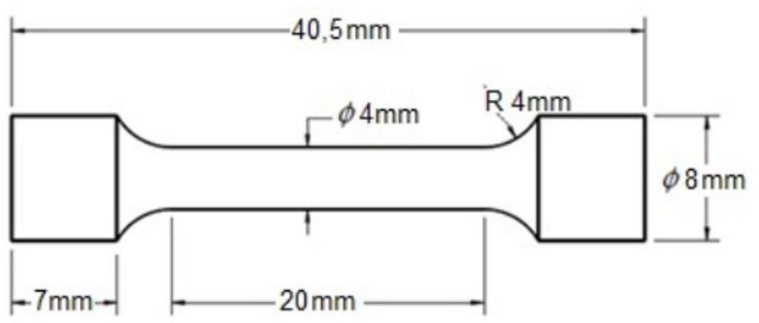

(c)

Figura 2. Esquema representativo dos corpos de prova: (a) amostras circulares usadas na medição da porosidade; (b) Posição dos corpos de prova de tração retirados das amostras circulares dos lingotes; (c) Corpos de prova para ensaios de tração.

Tabela 2. Composição química média (\% em massa) das Ligas I e II

\begin{tabular}{ccccccccc}
\hline & Al & Si & Fe & Cu & Mn & Mg & Zn & Outros \\
\hline Liga I & 95,17 & $\mathbf{3 , 8 0}$ & 0,35 & 0,14 & 0,08 & $\mathbf{0 , 2 5}$ & 0,08 & 0,13 \\
Liga II & 91,43 & $\mathbf{6 , 5 0}$ & 0,60 & 0,27 & 0,12 & $\mathbf{0 , 6 0}$ & 0,21 & 0,27 \\
\hline
\end{tabular}




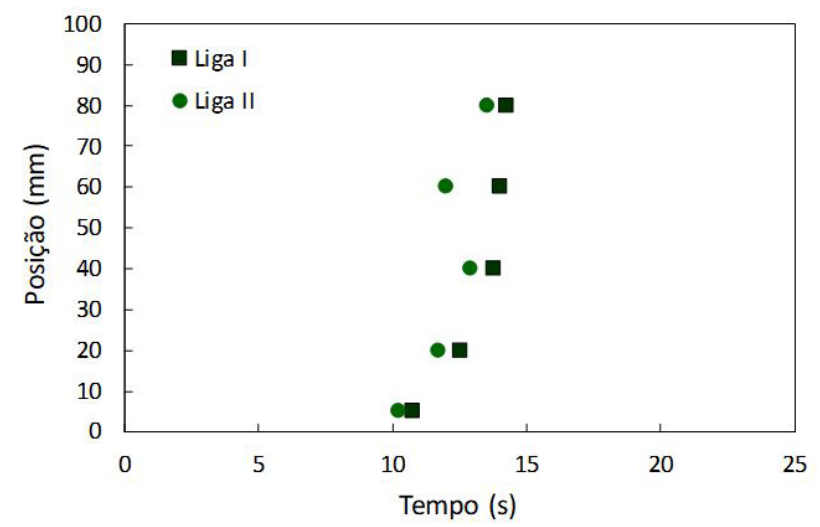

(a)

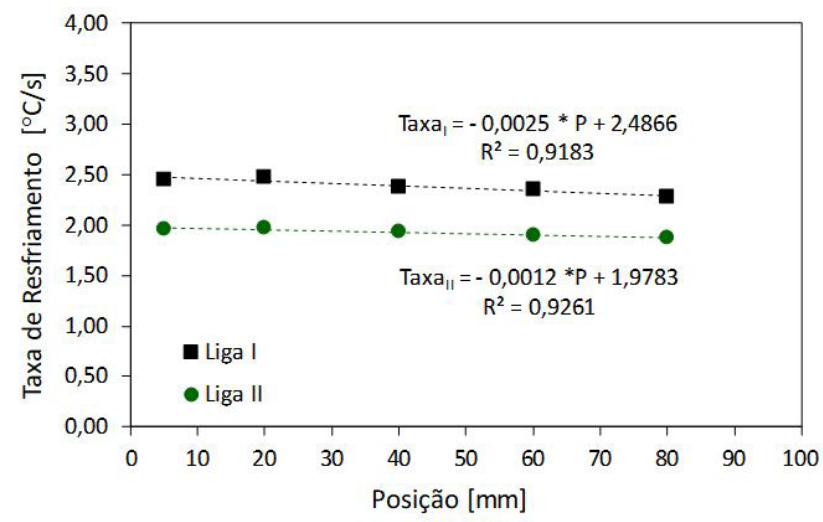

(b)

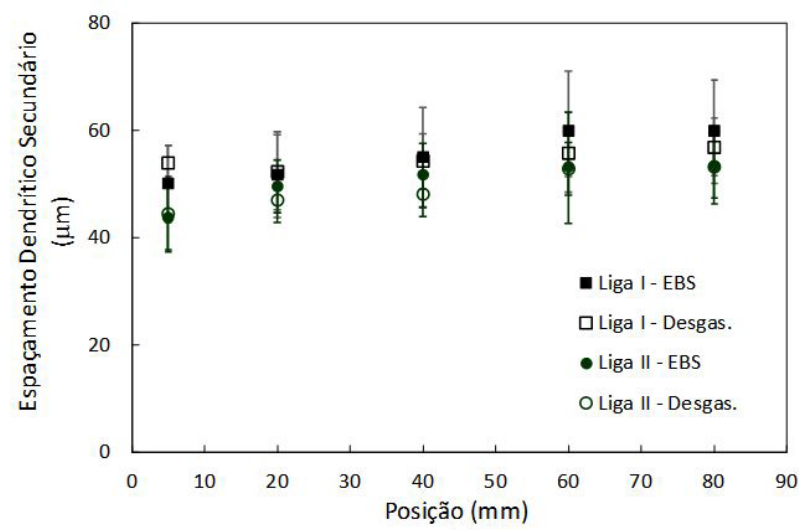

(c)

Figura 3. (a) Curvas de resfriamento das Ligas I e II; (b) taxas de resfriamento em função do tempo, e (c) espaçamentos dendríticos secundários em função da posição.

sendo que a Liga I apresentou valores levemente maiores do que a Liga II, muito provavelmente devido à maior difusividade térmica do material. Também foram medidos os espaçamentos dendríticos secundários nas diferentes posições, e o valores encontrados demonstram que as variações são menores que $10 \mu \mathrm{m}$ para ambas as ligas, e mantem-se praticamente constates para todas as posições. Apesar da Liga I apresentar taxas de resfriamento levemente maiores do que a Liga II, os espaçamentos dendríticos secundários foram maiores, o que permite afirmar que o teor de elementos de liga é fator predominante no refino dendrítico.

Durante a solidificação, segundo Patakham et al. [16], a taxa de resfriamento é a variável térmica de maior influência nas variações do tamanho de grão e dos espaçamentos dendríticos secundários. Segundo Dong et al. [17], o tamanho de grão e os espaçamentos dos braços dendríticos secundários apresentam influência nas propriedades mecânicas das ligas de alumínio. Sendo assim, devido à taxa de resfriamento apresentar-se praticamente constante, os espaçamentos dos braços dendríticos secundário, nas amostras ao longo do lingote, deverão apresentar pequenas variações, que se pressupõem que não irão influenciar na variação das propriedades mecânica das ligas em estudo.
A partir dos dados obtidos sobre o percentual volumétrico de porosidade, pôde-se gerar gráficos que acompanham a evolução do percentual de porosidade em função das diferentes condições e posições em análise, em ambas as ligas. Cabe salientar que, para a apresentação dos resultados, nas legendas dos gráficos a sigla "EBS" refere-se à condição bruta de solidificação e "desgas." refere-se à condição bruta de solidificação com tratamento de desgaseificação. A Figura 4 apresenta uma comparação entre os resultados experimentais do percentual (\%) de poros com a posição no lingote em relação à base da lingoteira. Na Figura 4 observa-se que as amostras da Liga II (Al-6,5\%Si-0,6\%Mg) apresentam maior percentual volumétrico de porosidade do que a Liga I (Al-3,8\%Si-0,25\%Mg), para ambas as posições e condições em análise.

A diferença de composição química das ligas pode explicar a diferença do percentual volumétrico de porosidade encontrado entre as ligas no estado bruto de solidificação. Conforme Moustafa [18], a presença do ferro facilita a formação de porosidade em ligas alumínio. Sendo assim, a Liga II por apresentar aproximadamente o dobro do teor de ferro $(0,6 \%$ de ferro) da Liga I, o que contribui para a maior formação de intermetálicos de ferro $\mathrm{Al}_{5} \mathrm{FeSi}$ (forma de agulhas) durante a solidificação, impedindo 
que o metal líquido possa preencher os espaços entre as agulhas ramificadas, apresente uma maior tendência a nucleação de poros.

A variação do percentual de porosidade em função da posição das amostras em relação à base da lingoteira, em ambas as ligas, é devido à presença do gás hidrogênio no alumínio líquido. Durante a solidificação, à medida que a viscosidade da massa líquida diminui, devido à queda de temperatura, fica mais difícil a fuga desses gases, os quais ficam retidos em maiores proporções nas proximidades da superfície dos lingotes, na forma de bolhas, resultando na presença de maior porosidade nas amostras retiradas de posições mais distantes da base da lingoteira.

As Ligas I e II, desgaseificadas com pastilha de Hexacloroetano, apresentaram reduções significativas no percentual volumétrico de porosidade comparadas com as mesmas ligas no estado bruto de solidificação sem desgaseificação. Mas cabe salientar que a amostra retirada da posição I (5 mm da base da lingoteira) da Liga I, após processo de desgaseificação, apresenta menor percentual volumétrico de porosidade, cerca de I,04\% em volume de porosidade. Esse nível de porosidade é considerado elevado, na visão de Gomes [19]. O nível de porosidade em ligas fundidas de alumínio deve ser menor que 0,5\% em volume, percentuais de porosidade mais elevados podem resultar propriedades mecânicas inferiores.

Após a realização dos ensaios de dureza, os dados de dureza das amostras circulares das Ligas I e II, referentes às condições e posições em análise, foram obtidos e podem ser visualizados na Figura 5. Com os ensaios de tração, obtiveram-se os valores de limite de resistência à tração dos corpos de prova retirados das amostras. Esses valores em relação às diferentes posições a partir da base da lingoteira podem ser visualizados na Figura 6.

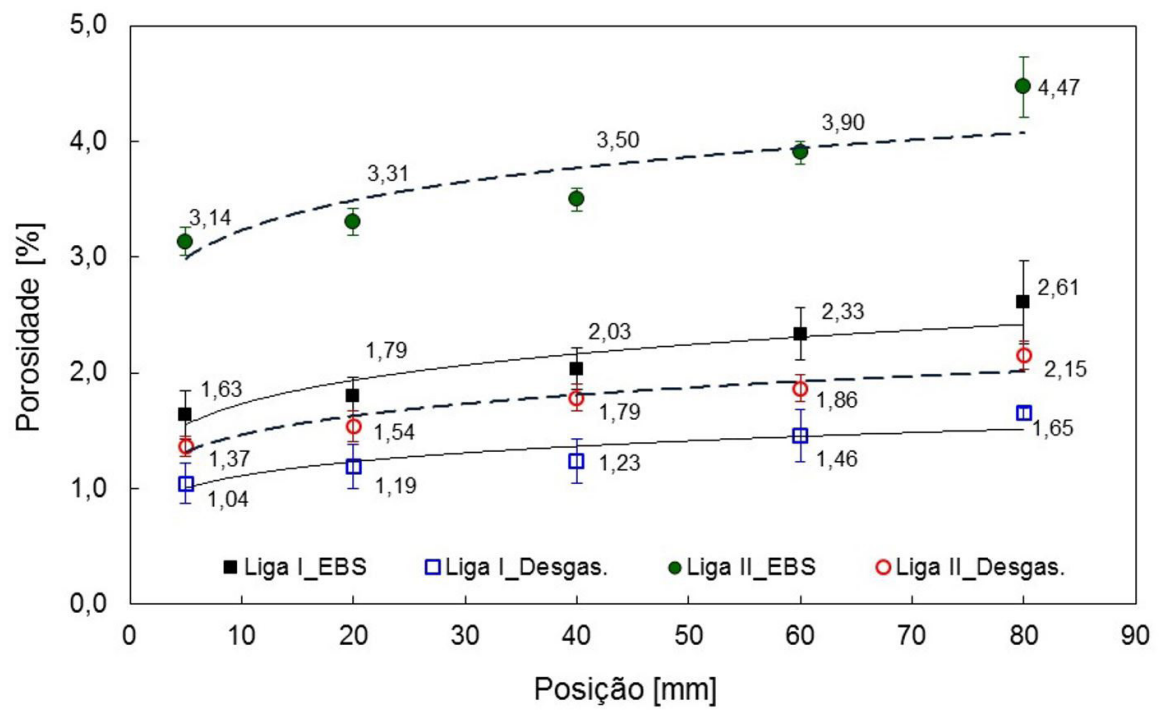

Figura 4. Percentual de porosidade em função da posição em relação à interface metal/molde (EBS: estrutura bruta de solidificação; Desgas: desgaseificada).

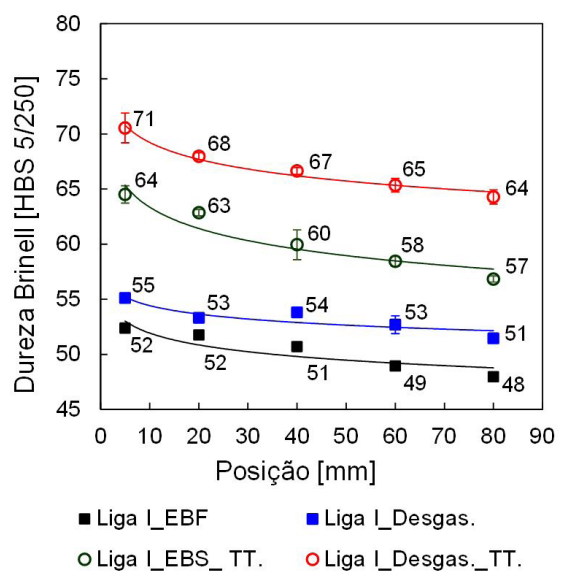

(a)

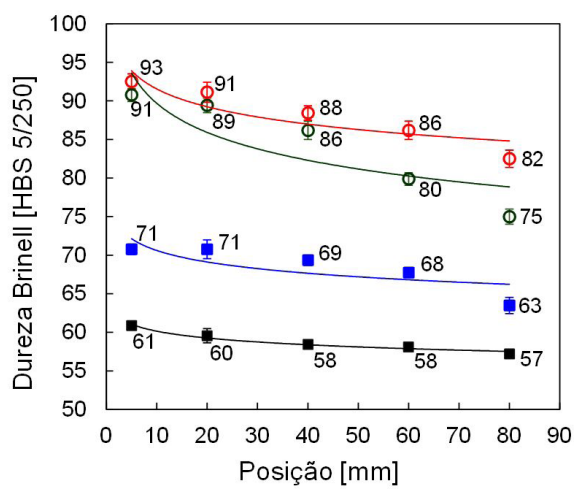

- Liga II_EBF - Liga II_Desgas.

oLiga II_EBS_ TT. OLiga II_Desagas._TT.

(b)

Figura 5. Durezas Brinell em função da posição nas diferentes condições de solidificação, com e sem aplicação do tratamento térmico: (a) Liga I, e (b) Liga II. 


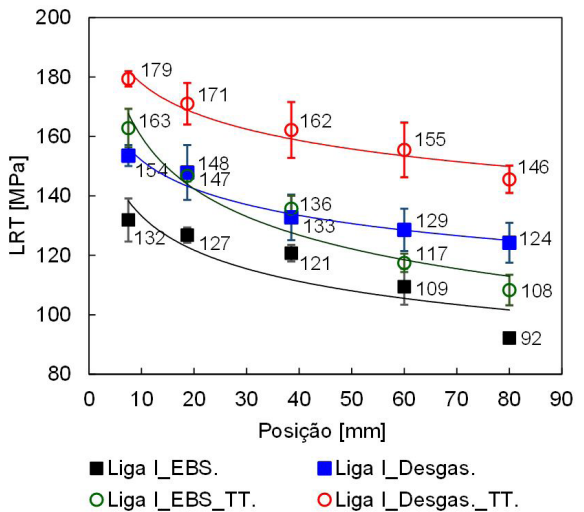

(a)

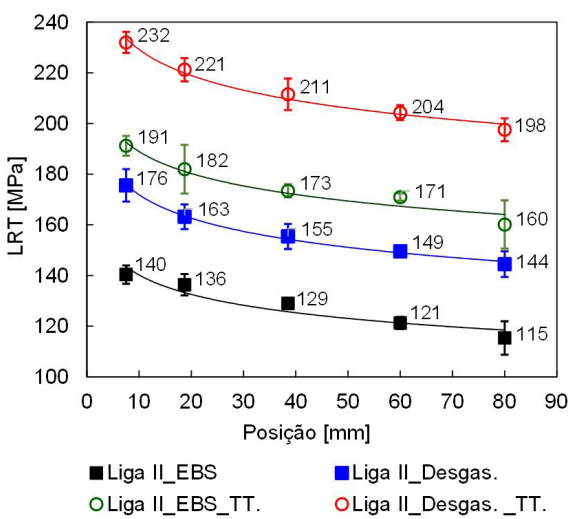

(b)

Figura 6. Limite de resistência à tração em função da posição nas diferentes condições de solidificação, com e sem aplicação do tratamento térmico: (a) Liga I, e (b) Liga II.

Em relação às Ligas I e II sem aplicação de tratamentos térmicos, analisando a Figura 5, observa-se que a Liga II (Al-6,5\%Si-0,6\%Mg) apresenta maiores valores de dureza Brinell do que a Liga I (Al-3,8\%Si-0,25\%Mg), nas condições brutas de solidificação e desgaseificadas. As amostras retiradas das posições mais próximas da base da lingoteira apresentaram os maiores valores de dureza Brinell, visto que, próximo à base da lingoteira apresenta-se menor percentual de porosidade, aumentando à resistência da liga e gerando maiores valores de dureza Brinell. Além do teor de porosidade, o teor de silício também influencia na diferença de dureza Brinell entre as Ligas I e II. Para Dwivedi et al. [20], o aumento do teor de Si provoca um aumento na proporção das fases de silício eutético que são mais duras que as fases de $\mathrm{Al}-\alpha$, isso pode resultar no aumento de dureza. $\mathrm{O}$ maior teor de magnésio na Liga II também é um favorecedor do aumento de dureza, uma vez que este forma solução sólida com o alumínio da matriz, e pode se combinar com o silício formando o intermetálico $\mathrm{Mg}_{2} \mathrm{Si}$, aumentando assim a resistência mecânica da liga [2 I].

Ainda sobre as Ligas I e II sem aplicação de tratamentos térmicos, na Figura 6, observa-se que as amostras referentes à Liga II apresentam maiores limites de resistência à tração do que as amostras da Liga I, tanto na condição bruta de solidificação quanto desgaseificadas, sendo que os menores limites de resistência à tração apresentam-se nas amostras retiradas de posições mais distantes da base da lingoteira, onde o efeito negativo da porosidade é maior.

Já em relação as Ligas I e II tratadas termicamente, observando as Figuras 5 e 6 é possível visualizar que a aplicação dos tratamentos aumenta a dureza e o limite de resistência à tração das amostras, nas condições sem desgaseificação e desgaseificadas. Com a aplicação do tratamento térmico T6, as amostras desgaseificadas da Liga ll apresentaram os maiores valores de dureza e limite de resistência à tração, atingindo $93 \mathrm{HB}$ e $232 \mathrm{MPa}$, respectivamente, na posição I, onde identificou-se o menor percentual volumétrico de porosidade, cerca de I,37\%. Sendo assim, observa-se que o processo de desgaseificação das ligas, juntamente com a aplicação do tratamento térmico T6, influenciou positivamente no aumento da dureza e limite de resistência à tração das ligas.

Analisando as Figuras 5 e 6 observa-se que a Liga II respondeu melhor a aplicação do tratamento térmico T6, em relação ao aumento na dureza e no limite de resistência à tração, e acredita-se que isso se deva principalmente a diferença de composição química entre as ligas. A Liga II apresenta maior percentual em massa de $\mathrm{Mg}$ (aproximadamente $0,6 \%$, enquanto que a Liga I apenas $0,25 \%$ ). O Mg é o elemento necessário para precipitação da fase $\mathrm{Mg}_{2} \mathrm{Si}$, base do endurecimento por precipitação e responsável pelas boas propriedades mecânicas nas condições de tratamento térmico [22].

As equações matemáticas que relacionam as propriedades mecânicas em função da composição química, percentual volumétrico de porosidade e as condições em análise (brutas de solidificação e tratadas termicamente), são apresentadas na sequência. Ressalta-se que em todas as equações geradas, como as variáveis referentes aos tratamentos térmicos foram qualitativos, os valores que podem assumir são " 0 " quanto o tratamento não existir e "I" quando tratamento existir.

A Equação 3 apresenta a relação entre o limite de resistência à tração (LTR), a composição química, percentual de porosidade e o tratamento térmico T6:

$$
\begin{aligned}
& \operatorname{LRT}(\mathrm{MPa})=87,3+23,85 \mathrm{Si}(\%)-97 \mathrm{Fe}(\%)+ \\
& 44,4 \mathrm{Mg}(\%)-20,29 \text { Porosidade }(\%)+37,00 T T_{-} \mathrm{T6}
\end{aligned}
$$

A Equação 4 apresenta a relação entre dureza, à composição química, percentual de porosidade e o tratamento térmico T6:

$$
\begin{aligned}
& \text { Dureza }(\mathrm{HB})=32,95+5,48 \mathrm{Si}(\%)+3,3 \mathrm{Fe}(\%)+ \\
& 16,0 \mathrm{Mg}(\%)-5,059 \text { Porosidade }(\%)+15,551 T T_{-} \mathrm{T6}
\end{aligned}
$$

Os resultados de coeficiente de determinação $\left(R^{2}\right)$, para as Equações 3 e 4, foram de $85 \%$ e $95 \%$, respectivamente. 
Sendo assim, os modelos estão bem ajustados e podem ser utilizados para predição. As Equações 3 e 4 são válidas para as ligas de Al-Si-Mg que apresentarem a composição química dentre os limites analisados $(6,5 \%-3,8 \% \mathrm{Si}, 0,6 \%-2,5 \%$ $\mathrm{Mg}$ e $0,6 \%-0,35 \% \mathrm{Fe}$ ), e obtidas mediante os mesmos processos e condições realizados nesse estudo.

Analisando as Equações 3 e 4, identificou-se o efeito negativo do percentual de ferro e porosidade no limite de resistência à tração, já o aumento do teor de silício, de magnésio e aplicação do tratamento térmico T6 contribuíram para maiores limites de resistência à tração e dureza.

\section{CONCLUSÕES}

Com relação à obtenção das ligas, foi possível desenvolver duas ligas com diferentes composições químicas: Liga I (Al-3,8\%Si-0,25\%Mg) e Liga II (Al-6,5\%Si-0,6\%Mg). Ressalta-se que durante o processo de solidificação das ligas, buscou-se manter as condições de solidificação semelhantes, com o intuito de manter-se as variáveis de solidificação ao longo dos lingotes constantes, evitando que as mesmas apresentassem influências significativas na variação das propriedades mecânicas das ligas.

Em relação à porosidade, identificou-se a presença de maior porosidade nas amostras retiradas de posições mais distantes da base da lingoteira. Já, o processo de desgaseificação reduziu em torno de $50 \%$ o percentual volumétrico de porosidade em todas as amostras.

Durante a análise das propriedades mecânicas das ligas nos estados bruto de solidificação, observou-se que as amostras referentes à Liga II, na condição desgaseificada, apresentaram maiores limites de resistência à tração e dureza. Sendo que, para as amostras retiradas da posição mais próxima da base da lingoteira, onde o efeito negativo da porosidade é menor, obteve-se o maior limite de resistência à tração e a maior dureza Brinell.

Quando se analisou as propriedades mecânicas após a aplicação dos tratamentos térmicos, pode-se concluir que o tratamento térmico (T6) proporcionou um aumento significativo no limite de resistência à tração e dureza de ambas as ligas. No entanto, foi na Liga II que se observou maior eficácia com a realização do tratamento térmico. Dessa forma, conclui-se que a Liga II, por apresenta maior percentual em massa de $\mathrm{Mg}$, respondeu melhor ao tratamento térmico, já que o $\mathrm{Mg}$ é o elemento necessário para precipitação da fase $\mathrm{Mg}_{2} \mathrm{Si}$, base do endurecimento por precipitação e responsável pela boa resistência à tração.

$\mathrm{Na}$ análise da correlação da composição química, percentual de porosidade e efeitos dos tratamentos térmicos com a variação nas propriedades mecânicas de dureza e limite de resistência à tração (LRT), foram determinadas equações matemáticas que se apresentam como uma solução viável para estimar essas propriedades em ligas de $\mathrm{Al}-\mathrm{Si}-\mathrm{Mg}$ fundidas, nas condições analisadas.

\section{REFERÊNCIAS}

I Gopikrishna S, Binu CY. Study of effects of T6 heat treatment on grain refined A3 I 9 alloy with magnesium and strontium addition. International Journal on Theoretical and Applied Research in Mechanical Engineering. 2013;2(3):59-62.

2 Serrano-Munoz I, Buffiere JY, Verdu C, Gaillar Y, Mu P, Nadot Y. Influence of surface and internal casting defects on the fatigue behaviour of A357-T6 cast aluminium alloy. International Journal of Fatigue. 2016;82(3):36I-370.

3 Kaeel AJ. Study the effect of solution treatment on mechanical properties of Al-7\%|Si-0.3\%Mg alloy. Natural and Applied Sciences. 2013;4:76-85.

4 ASM International. ASM Handbook Casting. Vol. 15, 9th. Ohio: AST International; 2002. Edition Metals Handbook.

5 Manente A, Timelli G. Optimizing the heat treatment process of cast aluminium alloys. INTECH Open Access Publisher. 201 I;9:197-220.

6 Dioni D, Cecchel S, Cornacchia G, Faccoli M, Panvini A. Effects of artificial aging conditions on mechanical properties of gravity cast B356 aluminum alloy. Transactions of Nonferrous Metals Society of China. 2015;25(4): 1035-1042.

7 Shabani MO, Mazahery A. Prediction of mechanical properties of cast a356 alloy as a function of microstructure and cooling rate. Archives of Metallurgy and Materials. 20I I;56(3):67I-675.

8 Dobrzanski LA, Borek W, Maniara R. Influence of the crystallization condition on Al-Si-Cu casting alloys structure. Journal of Achievements in Materials and Manufacturing Engineering. 2006; 18:2I I-2I4.

9 Puparattanapong K, Limmaneevichitr C. Effect of scandium on porosity formation in Al-6Si-0.3Mg alloys. The Indian Institute of Metals - IIM. 2016;69:1-8.

10 Bueno AW, Degreve L. Manual de laboratório de físico-química. São Paulo: McGraw-Hill; 1980.

II Moutinho DJC. Análise da evolução microestrutural e da formação de macrossegregação e microporosidade na solidificação unidirecional transitória de ligas ternárias Al-Cu-Si [tese]. Campinas: Universidade Estadual de Campinas; 2012. 
12 ASTM International. ASTM Standart B3I I-93 - Test Method for Density Determination for Powder Metallurgy (P/M) Materials Containing Less Than Two Percenty Porosity. West Conshohocken: ASTM International.

13 Ashby MF, Jones DRH. Engineering materials I: an introduction to properties, applications and design. 3rd ed. Oxônia: Butterworh Heinemann; 2005.

14 ASTM International. ASTM E8M-04 - Standard Test Methods for Tension Testing of Metallic Materials. West Conshohocken: ASTM International; 2004.

15 Associação Brasileira de Normas Técnicas. ABNT NBR NM ISO 6506-1:2010 - Materiais metálicos - ensaio de dureza Brinell. Rio de Janeiro: ABNT; 2010.

16 Patakham U, Kajornchaiyakul J, Limmaneevichitr C. Modification mechanism of eutectic silicon in Al-6Si-0.3 Mg alloy with scandium. Journal of Alloys and Compounds. 2013;575:273-284.

17 Dong QZ, Choi YS, Hong JH, Hwang HY. Prediction of mechanical properties of Al alloys with change of cooling rate. Overseas Foundry. 2012;9(4):67I-675.

18 Moustafa MA. Effect of iron content on the formation of $\beta$-Al5FeSi and porosity in Al-Si eutectic alloys. Journal of Materials Processing Technology. 2009;209(1):605-610.

19 Gomes LG. Microestrutura dendrítica, macrossegregação e microporosidade na solidificação de ligas ternárias Ai-Si-Cu [tese]. Campinas: Universidade Estadual de Campinas; 2012.

20 Dwivedi DK, Sharma R, Kumar A. Influence of silicon content and heat treatment parameters on mechanical properties of cast Al-Si-Mg alloys. International Journal of Cast Metals Research. 20I3;19(5):275-282.

2I Rana RS, Purohit R, Das S. Reviews on the influence of alloying elements on the microstructures and mechanical properties of aluminum alloys and aluminum composites. International Journal of Scientific and Research Publications. 20I2;2(6): I-7.

22 Kaygisiz Y, Maraşli N. Microstructural, mechanical and electrical characterization of directionally solidified Al-Si-Mg eutectic alloy. Journal of Alloys and Compounds. 2015;6I8:197-203.

Recebido em: 3 Abr. 2018

Aceito em: $15 \mathrm{Fev} .2019$ 